OPEN ACCESS

Edited by:

Zhi Sheng,

Virginia Tech, United States

Reviewed by:

Shiv K. Gupta,

Mayo Clinic Minnesota, United States

Yunbao Pan

Wuhan University, China

Sujuan Guo,

Dana-Farber Cancer Institute,

United States

${ }^{*}$ Correspondence:

Jing Liu

jiliuliuyswq@126.com

Rong Gui

aguirong@163.com

tThese authors have contributed equally to this work.

Specialty section:

This article was submitted to

Cancer Molecular Targets

and Therapeutics,

a section of the journal

Frontiers in Pharmacology

Received: 14 November 2017

Accepted: 25 January 2018

Published: 13 February 2018

Citation:

Fu Y, Li C, Luo Y, Li L, Liu J and

Gui R (2018) Silencing of Long Non-coding RNA MIAT Sensitizes Lung Cancer Cells to Gefitinib by Epigenetically Regulating miR-34a.

Front. Pharmacol. 9:82.

doi: 10.3389/fphar.2018.00082

\section{Silencing of Long Non-coding RNA MIAT Sensitizes Lung Cancer Cells to Gefitinib by Epigenetically Regulating miR-34a}

\author{
Yunfeng Fut, Chengyuan Lit, Yanwei Luo, Lian Li, Jing Liu* and Rong Gui* \\ The Third Xiangya Hospital of Central South University, Changsha, China
}

Long non-coding RNA (IncRNA) myocardial infarction associated transcript (MIAT) was recently identified as oncogene in several cancers. However, the role of MIAT on acquired resistance in lung cancer and the underlying mechanisms remain unclear. Here, we showed that the expression of MIAT in lung cancer tissues was upregulated compared with adjacent tissues. LncRNA MIAT expression was associated with tumor size, lymph node metastasis, distant metastasis and TNM stage. Univariate analysis and multivariate analysis revealed that the IncRNA MIAT to be an independent factor for predicating the prognosis of lung cancer patients. Low IncRNA MIAT have longer overall survival time and progression-free survival time than patients with high IncRNA MIAT expression. Moreover, the knockdown of MIAT significantly sensitized PC9 and gefitinib-resistant PC9 cells to gefitinib in vitro and in vivo, and increased the expression of miR-34a and inactivated PI3K/Akt signaling. MIAT interacted with miR-34a and epigenetically controlled the miR-34a expression by hyper-methylating its promotor. Taken together, our findings demonstrated that knockdown of MIAT by siRNA enhances lung cancer cells to gefitinib through the PI3K/Akt signaling pathway by epigenetically regulating miR-34a. Thus, MIAT may be a useful prognostic marker and therapeutic target for lung cancer patients.

\section{Keywords: long non-coding RNA, lung cancer, epigenetic, acquired resistance, c-Met}

\section{INTRODUCTION}

Lung cancer, including small-cell lung cancer (SCLC, accounting for about 20\%) and non-smallcell lung cancer (NSCLC, accounting for about $80 \%$ ), is a leading cause of cancer deaths worldwide. Amount of genomic and epigenomic alterations have been revealed during the development of lung cancer (Ma et al., 2017). The NSCLC cases often harbor epidermal growth factor receptor (EGFR) activating mutation. EGFR-tyrosine kinase inhibitors (EGFR-TKIs) are the first line chemotherapy drugs for EGFR-mutant NSCLC patients. However, acquired drug resistance often occurs on the continuous treatment (Zhang and Yuan, 2016). Once activated by ligands and receptor dimerization, EGFR can activate cellular signaling pathways such as the phosphoinositide 3-kinase (PI3K)-AKT pathway, ultimately leading to increased cell proliferation and survival. The mutations or genetic polymorphisms of EGFR may result in primary resistance on EGFR-TKIs, and gene copy 
alterations in pathways frequently induce acquired resistance, such as MET is considered one of the more common causes of acquired resistance in EGFR-mutant NSCLC (Rotow and Bivona, 2017). In addition, the epigenetic mechanisms are also indicated to be an important pathway for acquired TKI resistance (Stewart et al., 2015).

Long non-coding RNAs (lncRNAs) are a group of non-coding RNAs those length greater than 200 nucleotides. LncRNAs exhibit their functions through multiple biological mechanisms involving epigenetic, transcriptional, and post-transcriptional alterations (Chen Y. et al., 2016). Dysfunctions of lncRNAs are associated with tumorigenesis of various cancers, including lung cancer (Tian et al., 2017). Emerging evidence has revealed that lncRNAs play essential roles in drug resistance of cancer, such as glioma, bladder cancer, breast cancer and lung cancer (Niu et al., 2017). Li H. et al. (2017) revealed that lncRNA MALAT1 decreased the sensitivity of glioma cells to temozolomide by regulating ZEB1. LncRNA MEG3 overexpression induced cisplatin sensitivity of NSCLC cells by regulating miR-21-5p/SOX7 axis (Wang et al., 2017). LncRNA AK001796 increased the resistance of NSCLC cells to cisplatin through regulating cell apoptosis and cell proliferation (Liu et al., 2017). LncRNAs may serve as potential diagnostic biomarkers or therapeutic targets in lung cancer (Gong et al., 2017; Xue et al., 2017).

LncRNA MIAT was originally identified in myocardial infarction (MI) on chromosome 22q12 that confers risk of MI (Ishii et al., 2006). The following studies found that lncRNA MIAT was involved in various diseases, such as MI, diabetic retinopathy, paranoid schizophrenia, microvascular dysfunction and cancer (Liao J. et al., 2016; Zhou et al., 2017). LncRNA MIAT promoted breast cancer progression by regulating miR-155-5p to regulate DUSP7 expression in breast cancer (Luan et al., 2017), and promoted proliferation and invasion of hepatocellular carcinoma cells via regulating miR-214 (Huang et al., 2017). And Zhang HY showed that knockdown of MIAT substantially inhibited the invasive ability of NSCLC cells through the ZEB1 signaling pathway by regulating miR-150 (Zhang et al., 2017). However, whether MIAT plays a role on drug resistance in lung cancer remain unknown.

In this study, we focus on delineating role of lncRNA MIAT on drug resistance in lung cancer. We investigated the expression of MIAT in lung cancer tissues, and the association between MIAT and prognosis of lung cancer patients. Furthermore, we have analyzed role of MIAT in gefitinib resistance by employing genetic manipulation techniques. Our findings provide evidence that inhibition of MIAT may overcome EGFR-TKI acquired resistance in lung cancer.

\section{MATERIALS AND METHODS}

\section{Study Population}

Two hundred and twelve lung cancer tissues were collected from non-small cell lung cancer patients with mutant EGFR between February and April 2011. The patients who had prolonged stable disease of more than 6 months or a partial response and complete response to EGFR-TKIs therapy were defined as sensitive patients. The 2009 patients with progression on the first imaging evaluation or stable disease less than 6 months after EGFR-TKI treatment in the first setting were defined as primary resistance to EGFR-TKI. There are also 186 cases of adjacent tissue as a control. The present study was approved by the Ethics Committee of the Third Xiangya Hospital of Central South University. Written informed consent was obtained from the participants of this study.

\section{Cell Culture}

The human normal pulmonary epithelial cell BEAS-2B and the human lung cancer cell lines PC9, HCC827, A549, H1870, H1048, and H1299U87 were obtained from Chinese Academy of Medical Sciences (Beijing, China). Cells were cultured with Dulbecco's modified Eagle's medium (DMEM) containing 10\% fetal bovine serum (FBS, Gibco-BRL) and maintained in a humidified atmosphere of $5 \% \mathrm{CO}_{2}$ in air at $37^{\circ} \mathrm{C}$.

The gefitinib-resistant PC9 cell line (PC9/R) was established in our lab. The PC9 cells (EGFR mutations on exon 19; $1 \times 10^{5} / \mathrm{ml}$ ) were incubated for $24 \mathrm{~h}$, and then treated with the initial concentration of gefitinib $(0.5 \mu \mathrm{M})$. The medium containing gefitinib was changed once every $2-3$ days. When the initial dose was induced for 2 weeks, the drug dose was doubled, and each dose was maintained for 2 weeks. The final concentration was increased to $20 \mu \mathrm{M}$.

\section{Reagents}

The following antibodies were used in this study: GAPDH (Santa Cruz Biotechnology, Dallas, TX, United States), Bcl-2, Bax, cleaved caspase 3, c-Met, p-EGFR(pY1068), EGFR, p-PI3K(pY607), PI3K, p-Akt(pS473), Akt, Dnmt3a, Dnmt3b, and Dnmt1 (Abcam, United Kingdom). Gefitinib (cat no. SML1657) was obtained from Sigma-Aldrich.

\section{Cell Treatment}

The packaged lentivirus containing MIAT shRNA and empty vector control were purchased from Genepharma Company (Beijing, China). The PC9 and PC9/R cells were infected with these lentiviruses. Briefly, the cells $\left(2 \times 10^{5}\right.$ cells per well $)$ were seeded in 6-well plates and cultured until they reached $80-90 \%$ confluence. Then the cells were infected with lentivirus at multiplicity of infection (MOI) of 50 in the presence of $5 \mathrm{mg} / \mathrm{ml}$ polybrene (Sigma-Aldrich, St. Louis, MO, United States) for $48 \mathrm{~h}$.

Inhibition of miR-34a was performed using miR-34a inhibitor (GeneCopoecia, Guangzhou, China). The cells transfected with inhibitor control were used as negative control. Cells were plated in 6-well plates or 96-well plates and transfected for $24 \mathrm{~h}$ or $48 \mathrm{~h}$ by using Lipofectamine 3000 (Invitrogen) according to the manufacturer's instructions. Briefly, PC9 and PC9/R cells $\left(2 \times 10^{5}\right.$ cells per well $)$ were seeded separately in 6-well plates and cultured until they reached $80-90 \%$ confluence. Then, the cells were transfected with miR-34a inhibitors in serum- and antibiotic-free medium for $6 \mathrm{~h}$. Afterward, the medium was refreshed, and the cells were continuously cultured for $48 \mathrm{~h}$. 


\section{RNA Extraction and SYBR Green Quantitative PCR Analysis}

Total RNA was extracted from cells using Trizol reagent (Invitrogen, Carlsbad, CA, United States). Total RNA was reverse transcribed using a transcription kit (Invitrogen) to get total cDNA as templates for MIAT detection, or transcribed with Takara $^{\mathrm{TM}}$ microRNA transcription kit to get cDNA as templates for miR-34a detection. The expression of MIAT was measured by SYBR green qPCR assay (Takara, Dalian, China) according to manufacturers' instructions. Expression of $\beta$-actin was used as an endogenous control. MiR-34a expression was detected using a Hairpin-it TM miRNAs qPCR kit (Genepharma, Shanghai, China) according to manufacturers' instructions. Expression of RNU6B was used as an endogenous control. QPCR was performed at the condition: $95.0^{\circ} \mathrm{C}$ for $3 \mathrm{~min}$, and 39 circles of $95.0^{\circ} \mathrm{C}$ for $10 \mathrm{~s}$ and $60^{\circ} \mathrm{C}$ for $30 \mathrm{~s}$. Data were processed using $2^{-\Delta \Delta C T}$ method. The primers were used as following: 5' - TCCCATTCCCGGAAGCTAGA -3' (forward), 5' - GAGGCATGAAATCACCCCCA -3'(reverse) for MIAT. 5' - TTGTTACAGGAAGTCCCTTGCC-3' (forward), $5^{\prime}$ - ATGCTATCACCTCCCCTGTGTG-3' (reverse) for $\beta$-actin. Sequence of miRNA and references using in current study are: miR-34a: UGGCAGUGUCUUAGCUGGUUGU; RNU6B: CGCAAGGAUGACACGCAAAUUCGUGAAGCGUUCCAUA UUUUU. The reverse primers were also used in the Hairpin-it TM miRNAs qPCR kit.

\section{Cell Viability Assay and Colony Formation Assay}

Twenty-four hours before the experiment, the cells were plated in 96-well plates at a density of 1000 cells in $100 \mu \mathrm{l}$ medium per well. The cells were treated with a range of gefitinib, and the cell viability was assessed by CCK- 8 assay (Beyotime, Shanghai, China) according to the manufacturers' instructions.

For the colony formation assay, following treatment, adherent cells were trypsinized and 1000 viable cells were subcultured in six-well plates (in triplicate). Cells were allowed to adhere and cultured for 2 weeks in absence or presence of gefitinib as indicated. To visualize colonies, media were removed and cells were fixed in $96 \%$ ethanol for $10 \mathrm{~min}$, and then stained with $0.5 \%$ crystal violet (Beyotime) for $30 \mathrm{~min}$. The colonies were captured and counted.

\section{Flow Cytometry for Apoptosis Analysis}

Staining was performed by using Annexin V-FITC kit (KeyGEN BioTech, Nanjing, China) following the manufacturer's instructions. Briefly, $2 \times 10^{5}$ PC9 or PC9/R cells were harvested by centrifugation at $1000 \times g$ for $5 \mathrm{~min}$ and resuspended in $100 \mu \mathrm{l}$ binding buffer. The cells were incubated with $5 \mu \mathrm{l}$ Annexin V-FITC for $15 \mathrm{~min}$ in the dark at $37^{\circ} \mathrm{C}$ and then incubated with $10 \mu \mathrm{l}$ PI with gentle shaking for 10 min. Flow cytometry (FACSCanto II, Becton, Dickinson and Company) analysis was employed for detecting apoptotic events. FlowJo software v7 (FlowJo, LLC) was used to analyze the data.

\section{Western Blotting}

Cells were lysed in cold RIPA buffer, and the protein was separated with $10 \%$ SDS-PAGE, which was then transferred to PVDF membrane (Thermo Fisher). After that, the membrane was incubated in PBS with 5\% nonfat dried milk (Mengniu, Hohhot, China) for $3 \mathrm{~h}$. at $4^{\circ} \mathrm{C}$. Then, the membrane was incubated with primary antibodies overnight at $4^{\circ} \mathrm{C}$, and then with appropriate secondary antibody (Abcam) for $1 \mathrm{~h}$ at $37^{\circ} \mathrm{C}$. The immune complexes were detected using ECL Western Blotting Kit (Millipore).

\section{Luciferase Reporter Assay}

The fragment of $3^{\prime}$ UTR of MIAT containing the putative miR-34a binding site was amplified by PCR. The PCR product was subcloned into a psiCHECK-2 vector (Promega, Madison, WI, United States) immediately downstream to the luciferase gene sequence. A psiCHECK-2 construct containing 3'UTR of MIAT with a mutant seed sequence of miR-34a was also synthesized by Genepharma Co., Ltd. (Shanghai, China). All constructs were verified by DNA sequencing. The cells were plated in 96-well clusters, then cotransfected with $100 \mathrm{ng}$ constructs with or without miR-34a. At $48 \mathrm{~h}$ after transfection, luciferase activity was detected using a dual-luciferase reporter assay system (Promega, Madison, WI, United States) and normalized to Renilla activity.

For detecting the promoter activity of miR-34a, the putative promoter region (2500 bp upstream to miR-34a sequence) was synthesized and inserted into a pGL3-basic vector (Promega, Madison, WI, United States). The Dual-Luciferase Assay Kit was used to assess luciferase activities, following manufacturer's protocol. The PC9/R cells were plated in 96-well clusters, then cotransfected with 100 ng pGL3-basic vector or pGL3-miR-34a, together with MIAT siRNA or negative control. At $48 \mathrm{~h}$ after transfection, luciferase activity was detected using a dual-luciferase reporter assay system and normalized to Renilla activity.

\section{RNA Immunoprecipitation (RIP)}

RNA Immunoprecipitation experiments were performed using the Magna RIP RNA-Binding Protein IP Kit (Millipore, Bedford, MA, United States) and the Ago2, Dnmt3a, Dnmt3b or Dnmt1 antibody (Cell Signaling, Danvers, MA, United States) according to the manufacturer's instructions. The cells were scraped off and lysed in complete RIP lysis buffer for $30 \mathrm{~min}$. Then, $100 \mu \mathrm{l}$ of whole cell extract was incubated with RIP buffer containing magnetic beads conjugated with anti-Ago2, anti-Dnmt3a, anti-Dnmt3b or anti-Dnmt1 antibody overnight at $4^{\circ} \mathrm{C}$. Normal mouse IgG (Millipore) was used as negative control. Finally, purified RNAs in the precipitates were used to determine MIAT and miR-34a expression.

\section{Bisulfite Genomic Sequencing PCR (BSP) and Methylation Specific PCR (MSP)}

MiR-34a promoter methylation status was measured by MSP in tissues and BSP in cells. Genomic DNA was extracted using the Qiagen FFPE DNA Kit (Qiagen, Mountain View, CA, United States). Genomic DNA (1 $\mu \mathrm{g}$ per sample) was 


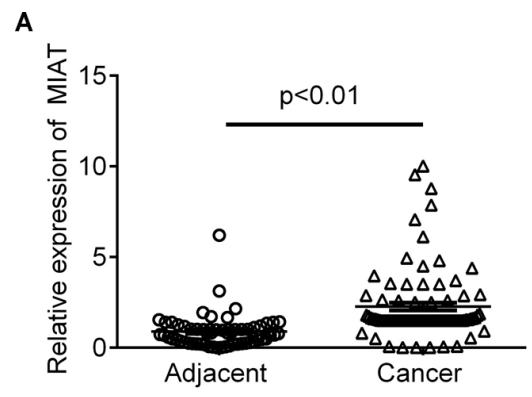

B
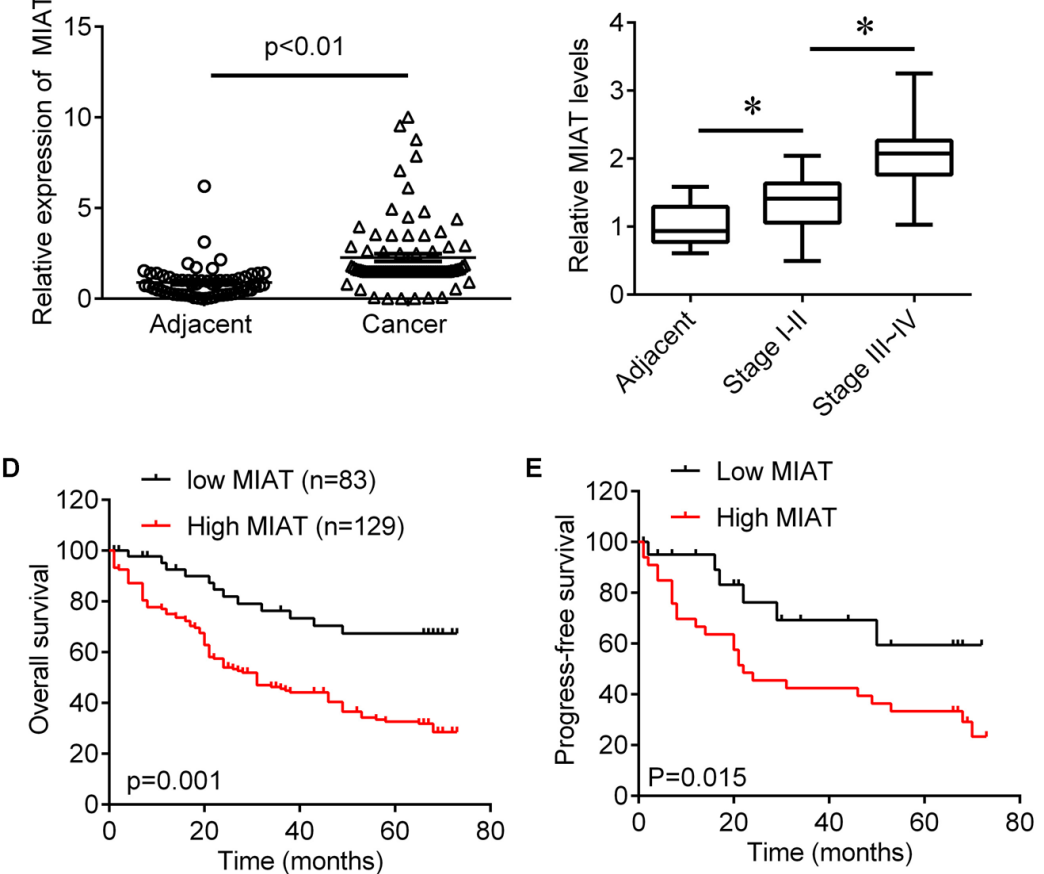

C

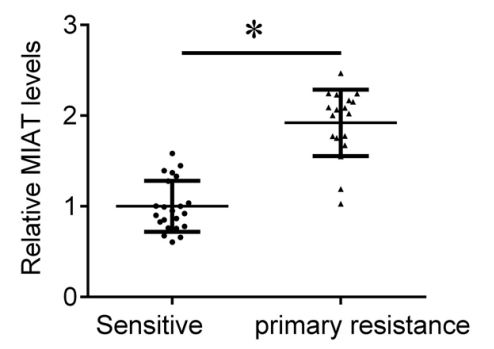

$\mathbf{F}$

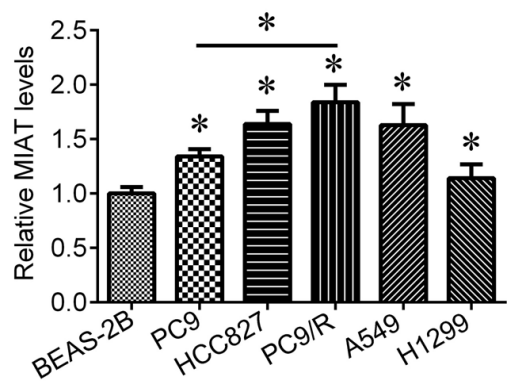

FIGURE 1 | The expression of MIAT in lung cancer tissues. (A) qRT-PCR was used to determine the expression of MIAT in NSCLC tissues ( $N=212$ ) and adjacent control $(N=186)$. (B) The expression of MIAT in adjacent tissues and grade I+II and grade III+IV lung cancer tissues. (C) The expression of MIAT in patients who sensitive $(N=45)$ or primary resistant $(N=25)$ to EGFR-TKI. (D) Overall survival analysis in NSCLC patients with low or high MIAT expression. (E) Progress-free survival analysis in NSCLC patients with low or high MIAT expression. (F) The expression of MIAT in BEAS-2B and lung cancer cell lines. ${ }^{*} P<0.05$.

modified with bisulfite using the EZ DNA Methylation-Gold Kit (Zymo, Orange County, CA, United States) according to the manufacturer's instructions. The PCR products were gel extracted (Qiagen) to confirm that a single band had been obtained and were then sequenced by Beijing Genomics Institute (Wuhan, China).

Methylation-specific PCR (MSP) was performed on bisulfatetreated DNA. The methylation and unmethylation primer sequences for miR-34a promotor were used as following: Methylated: forward, 5'-GGTTTTGGGTAGGCGCGTTTC-3', reverse, 5'-TCCTCATCCCCTTCACCGCCG-3'; unmethylated: forward, 5'-TGGTTTTGGGTAGGTGTGTTTT-3', reverse, 5'-AATCCTCATCCCCTTCACCACCA-3'. Bisulfite-modified DNA $(4 \mu \mathrm{l})$, the methylation $(3 \mu \mathrm{l})$ and unmethylation primer (3 $\mu$ l), 2X Taq PCR Master Mix (25 $\mu$ l, BioTeke, Beijing, China) and RNase-free water $(17 \mu \mathrm{l})$ were added to achieve a final volume of $50 \mu \mathrm{l}$. PCR amplification conditions were as follows: $95^{\circ} \mathrm{C}$ for $10 \mathrm{~min}, 94^{\circ} \mathrm{C}$ for $30 \mathrm{~s}$, annealing for $30 \mathrm{~s}$, and extension at $72^{\circ} \mathrm{C}$ for $45 \mathrm{~s}$; a total of 35 cycles; followed by a final extension at $72^{\circ} \mathrm{C}$ for $10 \mathrm{~min}$. A total of $10 \mu \mathrm{l}$ of the PCR product was separated using $2.5 \%$ agarose gel electrophoresis including GoldView I nuclear staining dyes (Solarbio, Beijing, China) for $30 \mathrm{~min}$, and the results were photographed and analyzed.

\section{Tumor Xenograft in Nude Mice}

Animal experiments were approved by the Ethical Committee for Animal Research of the Third Xiangya Hospital of Central South
University. The cells PC/R were transfected with MIAT siRNA or both MIAT siRNA and miR-34a inhibitor for $36 \mathrm{~h}$ before injection. To assess tumor growth, $100 \mu \mathrm{l}$ of the transfected $\mathrm{PC} / \mathrm{R}$ cells $\left(1 \times 10^{6}\right)$ was subcutaneously injected into BALB/C Nude mice ( 5 mice per group, 2 months-old). One day after injection, the mice were intragastrically administrated with gefitinib $(100 \mathrm{mg} / \mathrm{kg})$ once a day for 4 weeks. The tumor sizes were measured regularly and calculated using the formula: $0.5 \times L \times W^{2}$ where $L$ and $W$ are the long and short diameter of the tumor, respectively.

\section{Immunohistochemical (IHC) Staining}

The parrffin-embedded tumor sections of xenografts were serially cut at $4 \mu \mathrm{m}$. Slides were deparaffinized and dehydrated. Slides were retrieved in citric acid buffer ( $\mathrm{pH6.0)}$ by microwave oven. After cooling, the slices were blocked by normal goat serum, and incubated with primary antibody rabbit polyclonal anti-Ki67 antibody (1:100 dilution, Abcam) overnight at $4^{\circ} \mathrm{C}$. The sections were then washed with PBS and incubated with anti-rabbit secondary antibody for $2 \mathrm{~h}$ at $37^{\circ} \mathrm{C}$. The sections were then washed with PBS and stained by using DAB Detection Kit (Maxim, Xiamen, China). Finally, the sections were counterstained with hematoxylin. The images were obtained by using microscope (clipse Ni-E, Nikon, Japan). The quantification of positive signaling was obtained by Image-J. The data of Ki67 were acquired from eight fields/eight sections/animal and the data were averaged to produce a single value per subject. 
TABLE 1 | Clinical association between MIAT expression and clinicopathological variables in lung cancer patients.

\begin{tabular}{|c|c|c|c|}
\hline \multirow[t]{2}{*}{ Variable } & \multicolumn{2}{|c|}{ MIAT } & \multirow{2}{*}{$\begin{array}{l}\chi^{2} \text { test } \\
p \text { value }\end{array}$} \\
\hline & $\begin{array}{l}\text { Low expression } \\
\qquad(n=83)\end{array}$ & $\begin{array}{l}\text { High expression } \\
\quad(n=129)\end{array}$ & \\
\hline \multicolumn{4}{|l|}{ Age } \\
\hline$<60$ & 39 & 54 & 0.481 \\
\hline$\geq 60$ & 44 & 75 & \\
\hline \multicolumn{4}{|l|}{ Gender } \\
\hline Male & 50 & 84 & 0.560 \\
\hline Female & 33 & 45 & \\
\hline \multicolumn{4}{|l|}{ Tumor size } \\
\hline$<5 \mathrm{~cm}$ & 57 & 63 & 0.005 \\
\hline$\geq 5 \mathrm{~cm}$ & 26 & 66 & \\
\hline \multicolumn{4}{|l|}{ Histology type } \\
\hline Adenocarcinoma & 36 & 44 & 0.193 \\
\hline Squamous & 47 & 85 & \\
\hline \multicolumn{4}{|c|}{ Lymph node metastasis } \\
\hline No-1 & 51 & 54 & 0.007 \\
\hline N2-3 & 32 & 75 & \\
\hline \multicolumn{4}{|c|}{ Distant metastasis } \\
\hline No & 66 & 79 & 0.006 \\
\hline Yes & 17 & 50 & \\
\hline \multicolumn{4}{|l|}{ TNM stage } \\
\hline$|-| \mid$ & 63 & 72 & 0.003 \\
\hline |II-IV & 20 & 57 & \\
\hline
\end{tabular}

TABLE 2 | Univariate analysis of prognostic factors of lung cancer.

\begin{tabular}{lcc}
\hline Variable & Hazard ratio & $\boldsymbol{p}$ value \\
\hline Age $(\geq 60 /<60)$ & 1.46 & 0.55 \\
Gender (Male/Female) & 1.03 & 0.82 \\
Tumor size ( $\geq 5 \mathrm{~cm} /<5 \mathrm{~cm})$ & 2.64 & 0.02 \\
Histology type (Adenocarcinoma/Squamous) & 1.08 & 0.68 \\
Lymph node metastasis (NO-1/N2-3) & 3.24 & 0.01 \\
Distant metastasis (Yes/No) & 4.21 & 0.02 \\
TNM stage (III-IV/III) & 2.25 & 0.04 \\
MIAT expression (High/Low) & 2.74 & 0.03 \\
\hline
\end{tabular}

TABLE 3 | Multivariate analysis of independent prognostic factors of lung cancer.

\begin{tabular}{lcc}
\hline Variable & Hazard ratio & $\boldsymbol{p}$ value \\
\hline Tumor size & 2.36 & 0.04 \\
Lymph node metastasis & 2.87 & 0.01 \\
Distant metastasis & 3.69 & 0.02 \\
TNM stage & 2.74 & 0.02 \\
MIAT expression & 3.53 & 0.01 \\
\hline
\end{tabular}

\section{TUNEL Assay}

The TUNEL method was used for detecting DNA breaks by using a One Step TUNEL Apoptosis Assay Kit (cat no. C1088, Beyotime, Hangzhou, China) according to the manufacturer instructions. Tissues were counterstained with $4^{\prime}, 6$-diamidino2-phenylindole (DAPI). Fluorescent images were acquired with a Leica DM IRB epifluorescence microscope. The quantification of positive cells was obtained by Image-J. The data of luciferase intensity were acquired from eight fields/eight sections/animal and the data were averaged to produce a single value per subject.

\section{Statistical Analysis}

In this study, all experiments were repeated at least three times, and data are expressed as the mean \pm SEM SPSS 18.0 software package (SPSS, Chicago, IL, United States) was used to perform statistical analysis. The Inhibitory concentration 50 (IC50) values were taken from the minimal experimental concentration showing $50 \%$ cell death and calculated using GraphPad Prism 7. Difference between two groups was compared by independent-samples $t$ test. Difference among three or more groups was compared by One-Way ANOVA with post hoc Bonferroni test. The clinical association between MIAT expression and clinicopathological variables in lung cancer patients was evaluated by chi-square test. The $P$ value less than 0.05 were considered statistically significant.

\section{RESULTS}

\section{High IncRNA MIAT Is a Poor Predictor for Lung Cancer Prognosis}

To investigate role of lncRNA MIAT in lung cancer, we first evaluated the expression of lncRNA MIAT in lung cancer tissues. We found that lncRNA MIAT was significantly increased in lung cancer tissues compared with adjacent control (Figure 1A). In addition, the expression of IncRNA MIAT was higher in TNM stage III-IV than in TNM stage I-II (Figure 1B), suggesting the closed relationship of lncRNA MIAT in lung cancer development. Moreover, we divided the patients into two groups according to the median of lncRNA MIAT and found that lncRNA MIAT expression was associated with tumor size $(p=0.005)$, lymph node metastasis $(p=0.007)$, distant metastasis $(p=0.006)$ and TNM stage ( $p=0.003)$, but not associated with age $(p=0.481)$, gender $(p=0.560)$ and histology type $(p=0.193)$ (Table 1$)$. In addition, we investigated the factors that could predicate the prognosis of lung cancer patients by using the univariate and multivariate analyses. Univariate analysis indicated that the IncRNA MIAT level $(p=0.03)$, as well as the tumor size $(p=0.02)$, lymph node metastasis $(p=0.01)$, distant metastasis $(p=0.04)$ and TNM stage $(p=0.04)$ was significantly associated with patients' prognosis (Table 2). Multivariate analysis revealed that the IncRNA MIAT level $(p=0.01)$, the tumor size $(p=0.04)$, lymph node metastasis $(p=0.01)$, distant metastasis $(p=0.02)$ and TNM stage $(p=0.01)$ were found to be independent factors for predicating the prognosis of lung cancer patients (Table 3). Furthermore, we found that the patients with low lncRNA MIAT have longer overall survival time and progress-free survival time than that of with high lncRNA MIAT expression (Figures 1D,E). And we also wanted to know the expression of IncRNA MIAT in drug resistant lung cancer tissues and cell lines. Importantly, we found that the expression 
A

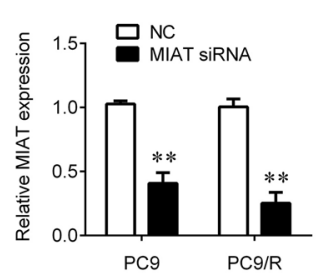

D

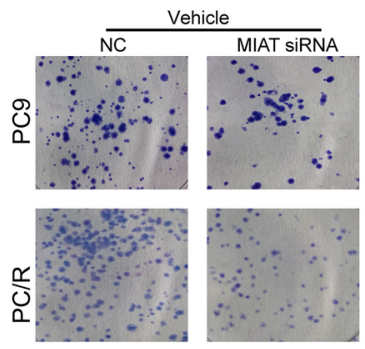

E

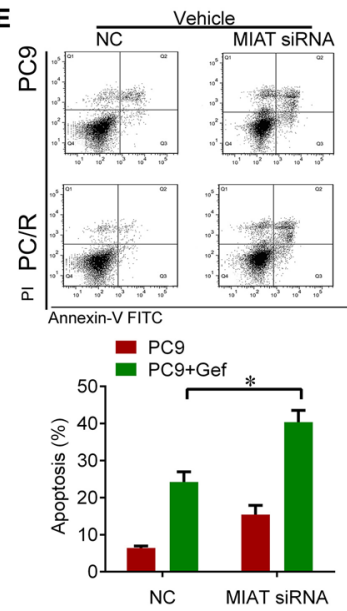

B

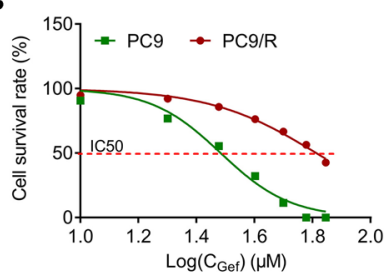

C

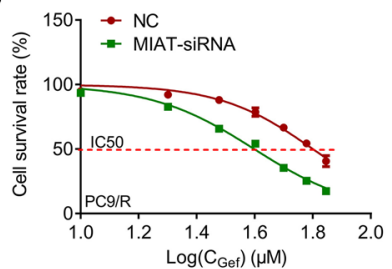

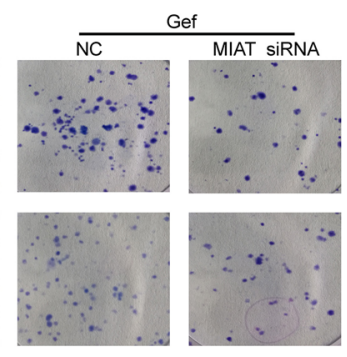
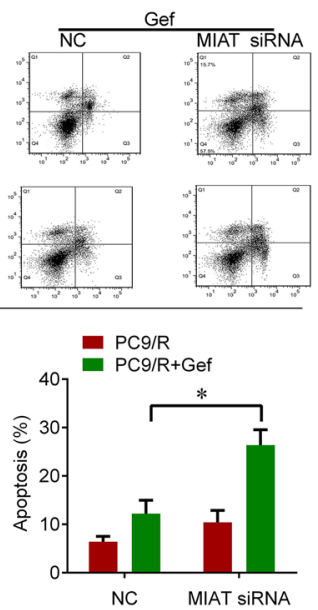
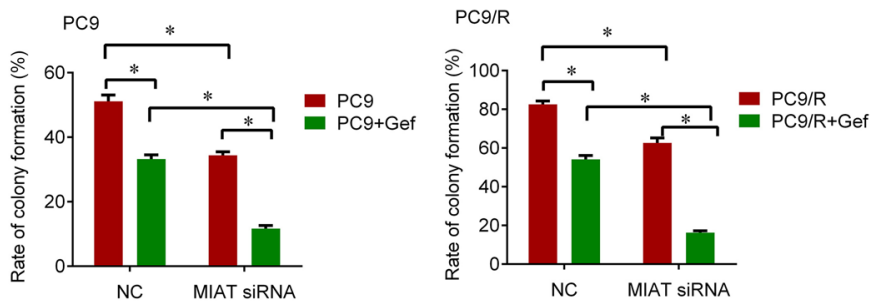

$\mathbf{F}$

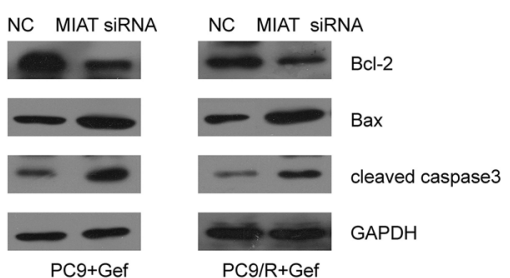

FIGURE 2 | Knockdown of MIAT sensitizes PC9 and PC9/R cells to gefitinib. (A) qRT-PCR analysis for MIAT in PC9 and PC9/R cells after transfection with MIAT siRNA or negative control. (B) CCK-8 assay was used to determine the IC50 in PC9 and PC9/R cells (PC9 vs. PC9/R: 29.05 vs. $62.61 \mu \mathrm{M})$. (C) CCK-8 assay was used to determine the change of IC50 in PC9/R cells after knockdown of MIAT (siMIAT vs.NC: 38.2 vs. $60.2 \mu \mathrm{M}$ ). (D) Colony formation assay was used to determine the cell growth after knockdown of MIAT and gefitinib treatment. (E) Flow cytometry was used to measure cell apoptosis after knockdown of MIAT and gefitinib treatment. (F) Western blot analysis for apoptosis marker Bcl-2, Bax and cleaved caspase 3 after knockdown of MIAT and gefitinib treatment. ${ }^{*} P<0.05$, ${ }^{* *} P<0.01$

of lncRNA MIAT was significantly increased in the patients who were primary resistant to EGFR-TKI $(N=26)$ compared with the patients who were sensitive to EGFR-TKI $(N=42)$ (Figure 1C). In line with in the tissues, the expression of lncRNA MIAT was also significantly increased in lung cancer cells compared with normal pulmonary epithelial cells BEAS$2 \mathrm{~B}$, and especially lncRNA MIAT was significantly increased in gefitinib-resistant PC9 (PC9/R) cells than in the parental cells (Figure 1F), indicating that upregulation of lncRNA MIAT may be involved in lung cancer drug resistance.

\section{Knockdown of IncRNA MIAT by siRNA Sensitizes Lung Cancer Cells to Gefitinib}

We further investigated whether knockdown of lncRNA MIAT expression could overcome the gefitinib resistance in PC9/R cells. We knocked down the expression of lncRNA MIAT in PC9 and PC9/R cells (Figure 2A). The IC50 of PC9/R was significantly higher than that of in PC9 cells (Figure 2B). Interestingly, we observed that knockdown of lncRNA MIAT significantly reduced IC50 in PC9/R cells (Figure 2C). Furthermore, we also found that knockdown of lncRNA MIAT enhanced the inhibitory effects of gefitinib on the inhibition of cell proliferation and promotion of cell apoptosis evaluated by significantly reduced colony formation (Figure 2D) and the significant increase of apoptosis rate as compared to the negative control (Figure 2E). We also found that knockdown of lncRNA MIAT decreased the $\mathrm{Bcl}-2$ expression and increased the Bax and cleaved caspase 3 expression (Figure 2F). Thus, knockdown of lncRNA MIAT can overcome gefitinib resistance in lung cancer cells.

\section{LncRNA MIAT Mediates Hypermethylation of miR-34 Promotor}

Bioinformatics analysis was used to search for the potential targeted microRNAs of IncRNA MIAT, such as MiRcode, 
A

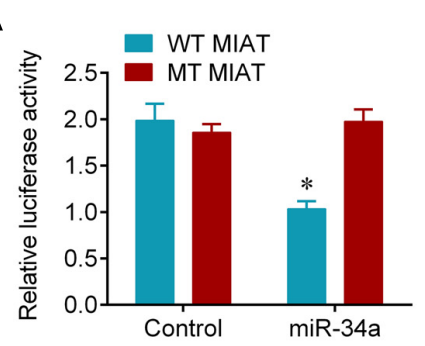

D

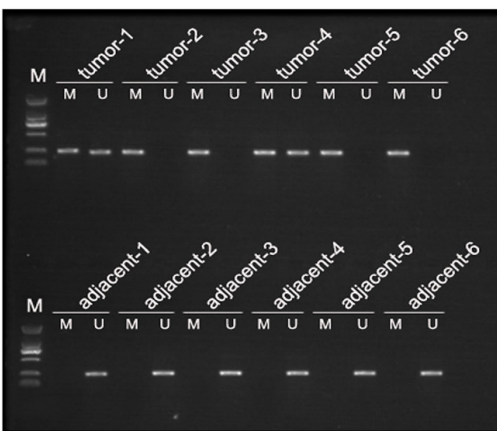

G

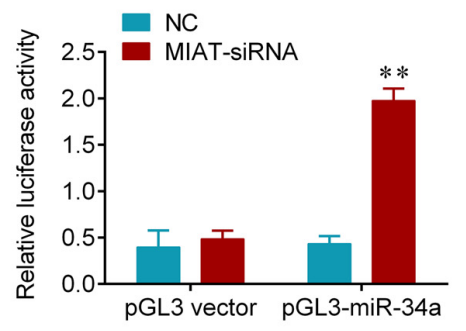

B

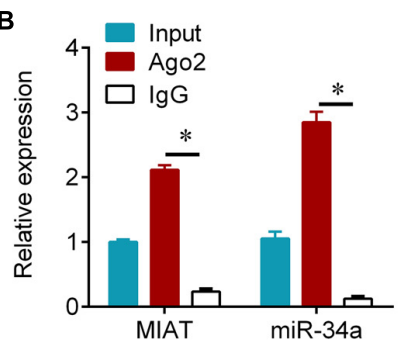

E

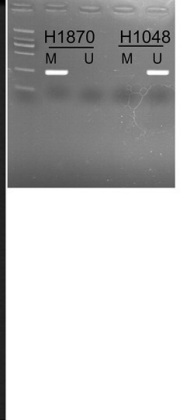

H

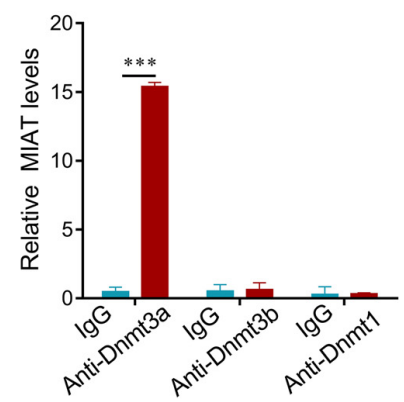

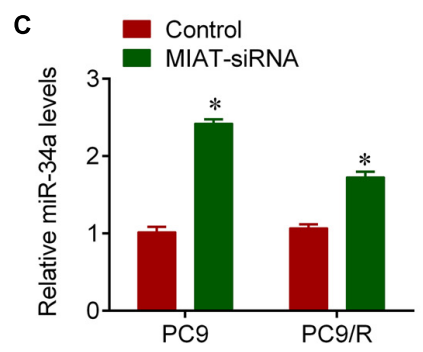

F
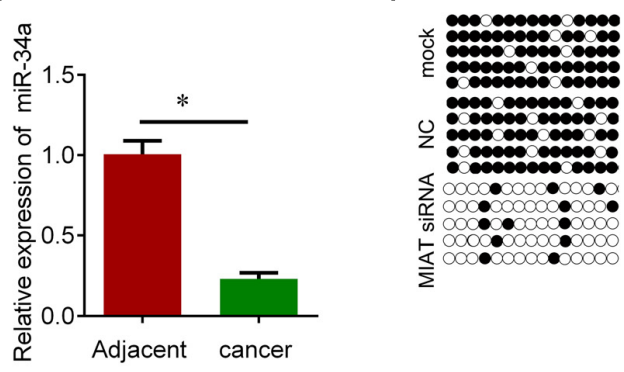

I

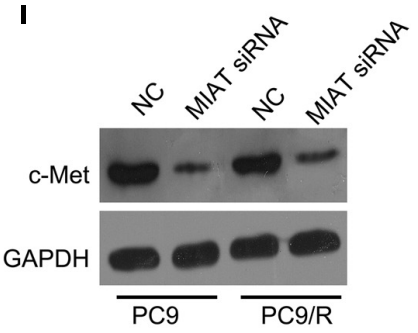

FIGURE 3 | MIAT epigenetically regulates miR-34a. (A) The relative luciferase activities were inhibited in the PC9 cells co-transfected with wild-type MIAT 3'UTR vector and miR-34a, but not with the mutant-type vector. Firefly luciferase activity was normalized to Renilla luciferase. (B) Association of MIAT and miR-34a between with Ago2 in PC9 cells. Cellular lysates from PC9 cells were used for RIP with antibody against Ago2. MIAT and miR-34a expression levels were detected using qRT-PCR. (C) qRT-PCR analysis for miR-34a in PC9 and PC9/R cells after transfection with MIAT siRNA or negative control. (D) MSP test results indicated that methylation of miR-34a promoter was higher in lung cancer tissues than that of in matched adjacent tissues. $\mathrm{H} 1870$ cells were used as positive control and $\mathrm{H} 1048$ cells were used as negative control. M, methylation; $U$, unmethylation. (E) qRT-PCR analysis for miR-34a in lung cancer tissues and matched adjacent tissues in (D) $N=6$. (F) The BSP detection results demonstrated that methylation of miR-34a was decreased after MIAT siRNA transfection in PC9 cells. Solid circle, methylation; hollow circle, unmethylation. PCR products amplified from bisulfite-treated genomic DNA were cloned and sequenced to reveal the methylation status of individual CpG sites. Percentages of the methylated CpG sites (filled circles) among all scored sites are indicated. (G) Luciferase reporter analysis of luciferase activity in PC9 cells cotransfected with pGL3-miR-34a and MIAT siRNA lentivirus or an empty lentivirus. (H) Association of MIAT and Dnmts in PC9 cells. Cellular lysates from PC9 cells were used for RIP with antibody against Dnmt3a, Dnmt3b or Dnmt1. MIAT expression levels were detected using qRT-PCR. IgG was used as a negative control. (I) Western blot analysis for validated miR-34a target, c-Met after indicated treatment. GAPDH was used a loading control. ${ }^{*} P<0.05$, ${ }^{* *} p<0.01,{ }^{* * *} p<0.001$.

RNAplex, catRAPID omics. Together, miR-34a was found to be a conserved target of lncRNA MIAT. To investigate if the predicted binding site of miR-34a to $3^{\prime} \mathrm{UTR}$ of lncRNA MIAT is responsible for this regulation, we cloned the $3^{\prime} \mathrm{UTR}$ of lncRNA MIAT downstream to a luciferase reporter gene (WT MIAT), its mutant version (MT MIAT) by the binding site mutagenesis was also constructed. The luciferase activity of cells co-transfected miR-34a and WT MIAT was significantly reduced compared to negative control cells. Moreover, miR-34a-mediated repression of luciferase activity was abolished by the mutant putative binding site (Figure 3A). The RNA-induced silencing complex (RISC) is a major mechanism of miRNAs to silence target genes, and Ago2 protein is a key constituent of RISC complex. To validate the presence of both miR-34a and lncRNA MIAT in the RISC complex, a RIP experiment was conducted using Ago2 antibody to confirm that both miR-34a and lncRNA MIAT were found in the Ago2 pellet (Figure 3B). We then wanted to know whether lncRNA MIAT can regulate the expression of miR-34a. We found that knockdown of lncRNA MIAT significantly increased the expression of miR-34a in PC9 and PC9/R cells (Figure 3C). And these regulatory effects subsequently influence the expression of targets of miR-34a. Knockdown of lncRNA MIAT significantly reduced the expression of c-Met, a validated target of miR-34a (Figure 3I). 

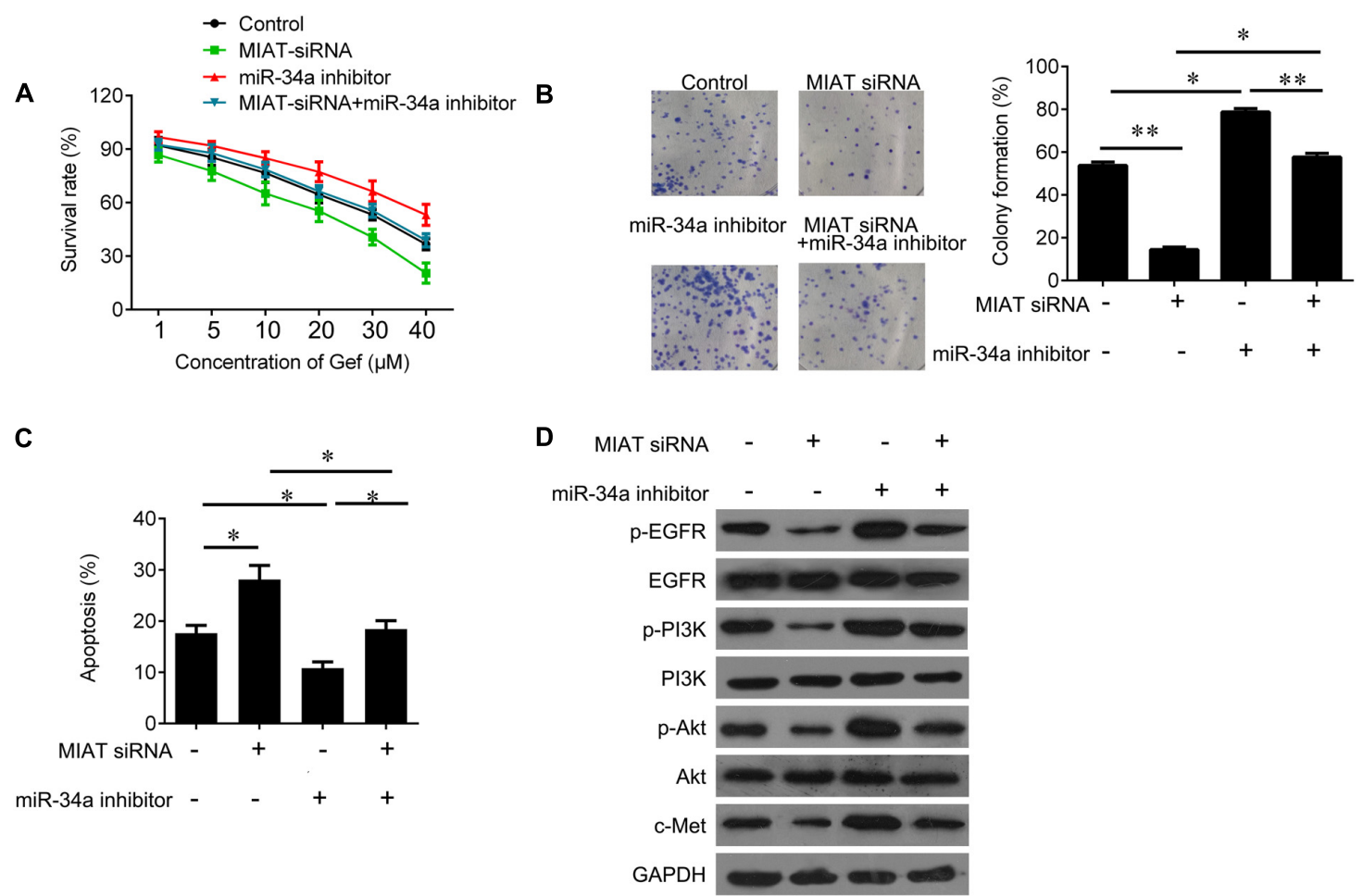

FIGURE 4 | MiR-34a inhibitor reverses the inhibitory effects of MIAT downregulation on PC9 cells. (A) CCK-8 assay was used to determine the cell viability after miR-34a inhibitor and MIAT siRNA treatment in PC9 cells. (B) Colony formation assay was used to determine the cell growth after miR-34a inhibitor and MIAT siRNA treatment in PC9 cells. (C) Flow cytometry was used to measured cell apoptosis after miR-34a inhibitor and MIAT siRNA treatment in PC9 cells. (D) Western blot analysis for p-EGFR, EGFR, p-PI3K, PI3K, p-AKT, AKT and c-Met after miR-34a inhibitor and MIAT siRNA treatment in PC9 cells. ${ }^{*} P<0.05$, ${ }^{* *} P<0.01$.

We further investigated how lncRNA MIAT controls the expression of miR-34a. Promotor hypermethylation of miR-34a has been found in various cancers (Schmid et al., 2016). We here also found that the promotor of miR-34a was hyper-methylated in primary resistant lung cancer tissues, but not found in adjacent tissues; $\mathrm{H} 1870$ and $\mathrm{H} 1048$ cells were used as positive and negative control for methylation of miR-34a (Tanaka et al., 2012) (Figure 3D). And the expression of miR-34a was significantly downregulated in these lung cancer tissues compared with adjacent tissues (Figure 3E). Interestingly, we observed that knockdown of IncRNA MIAT diminished hypermethylation of miR-34a promoter (Figure 3F). And dual-Luciferase reporter analysis showed that knockdown of IncRNA MIAT could activate the activity of miR-34a promotor (Figure 3G). Moreover, RIP experiment results showed that MIAT could interact with Dnmt3a but not Dnmt3b and Dnmt1 (Figure 3H). These results indicate that lncRNA MIAT can epigenetically control miR-34a expression by recruiting Dnmt3a to miR-34a promotor in lung cancer cells.

\section{LncRNA MIAT Sensitizes Lung Cancer Cells to Gefitinib through miR-34a and PI3K/Akt/c-Met Signaling}

Due to the regulatory effect between IncRNA MIAT and miR-34a, we further tested the biological role of interaction between
IncRNA MIAT and miR-34a. PC9 cells were transfected with MIAT siRNA or miR-34a inhibitor alone, or both combined. We found that down-regulated miR-34a largely attenuated MIAT siRNA-mediated inhibition of cell survival (Figure 4A) and clonogenic ability (Figure 4B), and induction of cell apoptosis (Figure 4C). In addition, we found that knockdown of lncRNA MIAT could inactivate PI3K/Akt/c-Met signaling, whereas miR-34a inhibitor reversed this inactivation of PI3K/Akt/c-Met signaling (Figure 4D). Moreover, we also confirmed these results in vivo. Compared with $\mathrm{NC}$ control group, knockdown of lncRNA MIAT significantly inhibited tumor growth (Figure 5A). And knockdown of IncRNA MIAT inhibited the Ki67 expression and increased the TUNEL positive cells (Figures 5B,C). However, these inhibitory effects were reversed by miR-34a inhibitor (Figure 5). And we also confirmed the regulatory effects of MIAT on PI3K/Akt/c-Met signaling in xenografted tissues (Figures 5D,E). In addition, qRT-PCR performed in human lung cancer tissues with high $(n=5)$ or low $(n=5)$ MIAT expression showed that miR-34a expression is negatively correlated with MIAT expression (Figure 5F). As shown in schematic diagram of mechanism of MIAT epigenetically regulating miR-34a (Figure 6). It is possible that MIAT interacts with Dnmt3a and recruits it on miR-34a promotor to hyper-methylate miR-34a, reducing miR-34a expression and subsequent increasing c-Met expression. The results indicate that lncRNA MIAT enhances gefitinib resistance in lung cancer cells via targeting miR-34a. 


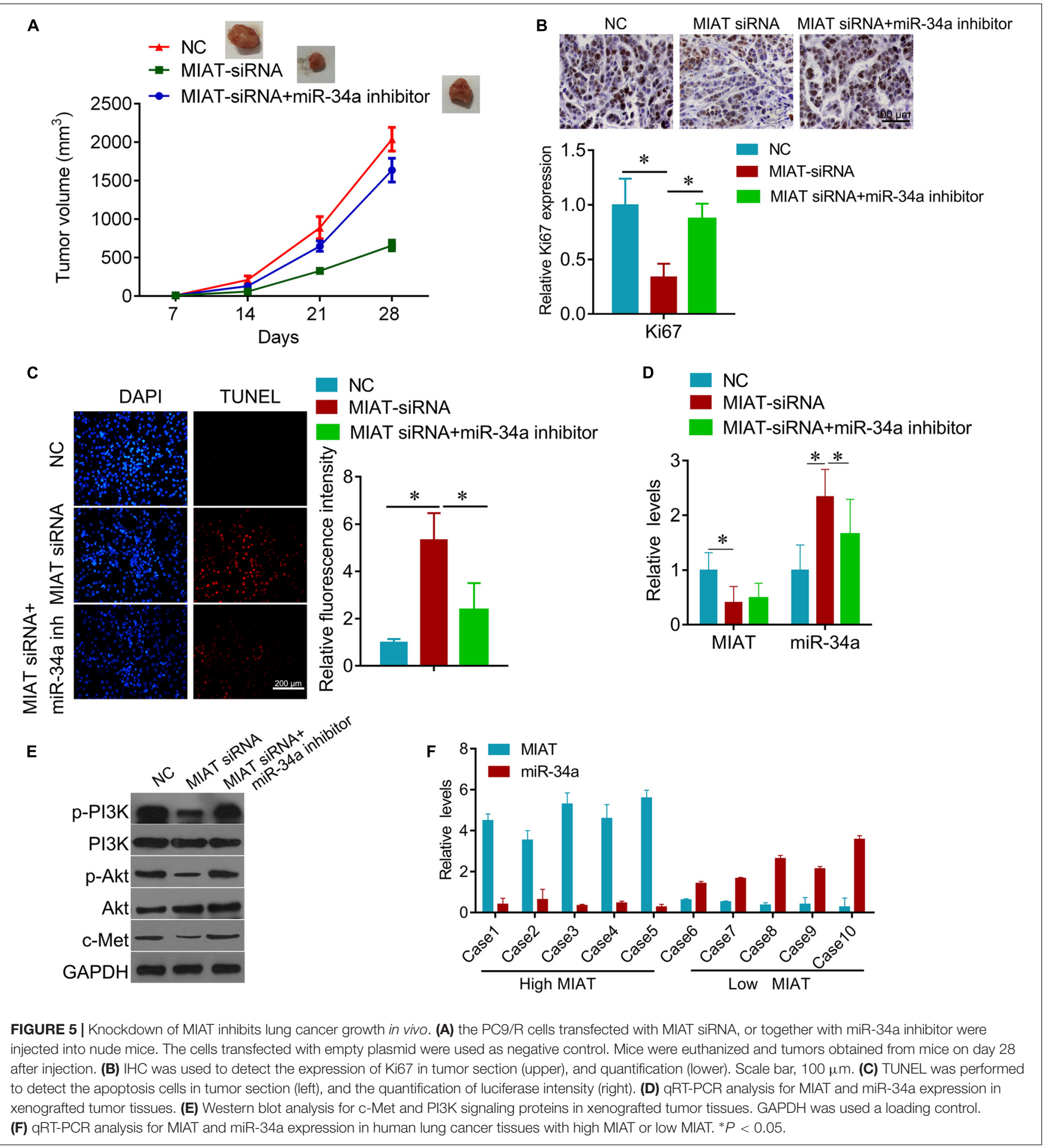

\section{DISCUSSION}

In this study, we found that IncRNA MIAT was upregulated in lung cancer tissues compared with adjacent tissues, and the patients with low IncRNA MIAT had longer overall survival time and progression-free survival time than patients with high IncRNA MIAT expression. LncRNA MIAT may be an independent factor for predicating the prognosis of lung cancer patients. Increasing evidence indicates lncRNAs can be prognostic factors for lung cancer patients. Qu $\mathrm{CH}$ et al showed that higher expression of linc-ROR predicted significantly shorter 5 -year overall survival and disease-free survival (DFS) in patients with NSCLC (Qu C.H. et al., 2017). LncRNA HOTTIP was overexpressed in small cell lung cancer tissues, and its expression 


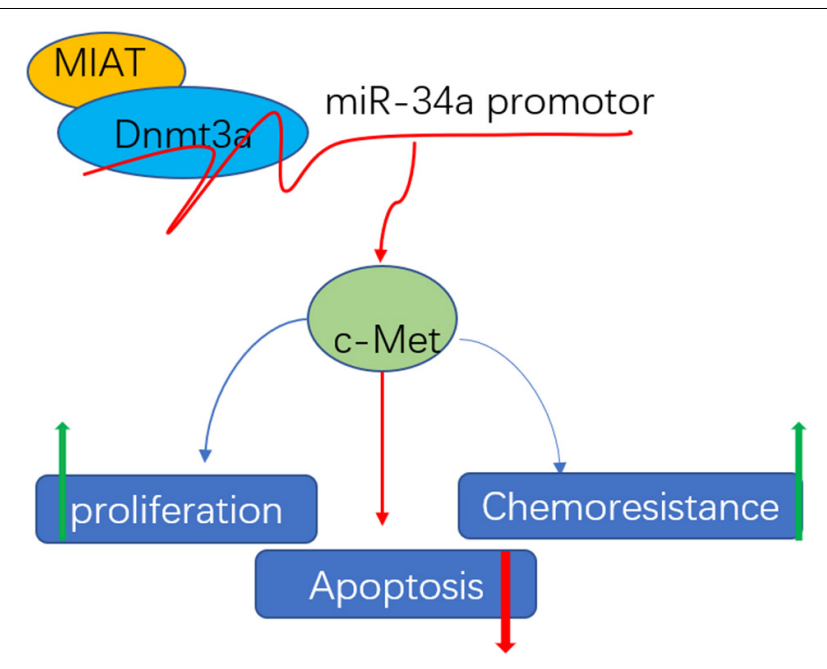

FIGURE 6 | Schematic diagram of mechanism of MIAT epigenetically regulating miR-34a. MIAT interacts with Dnmt3a and recruits it on miR-34a promotor to hyper-methylate miR-34a, increasing c-Met expression, and finally conferring chemoresistance, promoting proliferation and inhibiting apoptosis.

was correlated with the clinical stage and the shorter survival time of small cell lung cancer patients (Sun et al., 2017). Serum lncRNA AFAP1-AS1 could be used as molecular marker for distinguishing non-small cell lung cancer patients from healthy people, and high serum lncRNA AFAP1-AS1 expression levels correlated with distant metastasis, lymph node metastasis, poor clinical stage, and larger tumor size (Li W. et al., 2017). Our results in this study population showed that the 5-year overall survival was about $25 \%$ in MIAT-High group, and about $60 \%$ in MIAT-Low group. The cancer statistics in China predicted that $36.9 \%$ of cancer patients in China will survive at least 5 years after diagnosis; and the lowest survival rates were found in Southwest China (24.9\%), with Central China showing the highest rate (41.0\%) (Chen W. et al., 2016). And the lung cancer 5 year-survival rate in United States from 2002 to 2008 was about $30 \%$ (Siegel et al., 2013; Torre et al., 2015). Thus, the 5-year overall survival in MIAT-High group (25\%) in our study population was significantly lower, and the survival in MIAT-Low group was higher than the historical survival rate. However, we cannot exclude the difference in race and region. The subjects in this study mainly come from Hunan province (located on Central China) with relatively higher survival rate in China. Thus, we concluded that the expression of MIAT can be used to predict the outcome of patients with lung cancer.

Previous studies demonstrated that MIAT was highly expressed in cardiomyocytes, and involved in MI (Qu X. et al., 2017), diabetic cardiomyopathy (Zhou et al., 2017), ischemic stroke (Zhu et al., 2017), angiogenesis (Yan et al., 2015; Jiang et al., 2016). Recently, MIAT was found to be an oncogenic lncRNA in various cancers. Crea et al. (2016) found that LncRNA MIAT was selectively upregulated in neuroendocrine prostate cancer and might interact with Polycomb genes. Knockdown MIAT inhibited breast cancer cell proliferation, promoted apoptosis and decreased migration and invasion by acting as a competing endogenous RNA to regulate the expression of dual specificity phosphatase 7 by taking up miR-155-5p (Luan et al., 2017). Upregulation of MIAT was also related to the proliferation and invasion of hepatocellular carcinoma and gastric cancer by releasing miR-214 and miR-29a, respectively (Huang et al., 2017; Li Y. et al., 2017). By RNA-seq data and miRNA-seq data of lung adenocarcinomas, Li et al. (2016) identified three differentially expressed lncRNAs, including MIAT, were associated with clinical features involved in MAPK signaling pathways. And Zhang HY demonstrated that knockdown of MIAT significantly downregulated the expression of the zinc finger E-box binding homeobox 1 (ZEB1) through suppressing miR-150 to inhibit cell invasion of NSCLC cells (Zhang et al., 2017). Importantly, we here report that the expression of MIAT was significantly increased in patients who were primary resistant to EGFR-TKIs compared with the sensitive patients. And knockdown of MIAT by siRNA could sensitize lung cancer cells to gefitinib.

Interestingly, we found that MIAT interacted with miR34a, and epigenetically and negatively regulated miR-34a expression by hypermethylating its promotor to control c-Met expression. Knockdown of MIAT also enhanced gefitinib cytotoxicity through inactivating PI3K/AKT signaling, an important pathway to promote cancer cell proliferation (De Marco et al., 2017). MiR-34a is an important tumor suppressor whose expression is epigenetically silenced in various human cancers (Saito et al., 2015; Adams et al., 2016). And hypermethylation of miR-34a promotor resulted in miR-34a silence in prostate cancer (Liao H. et al., 2016), ovarian cancer (Schmid et al., 2016), cholangiocarcinoma (Kwon et al., 2017), laryngeal squamous cell carcinoma (Shen et al., 2016), and lung cancer (Kim et al., 2017). Zhou et al. (2014) found that miR-34a rescued hepatocyte growth factor-induced gefitinib resistance in EGFR mutant NSCLC cells by inhibiting activity of the PI3K/Akt pathway. Zhao et al. (2017) also demonstrated that combined miR-34a mimics and EGFR-TKIs synergistically sensitized both EGFR wild-type and mutant NSCLC cells. The hypermethylation of miR-34a promotor was mediated by several DNA methyltransferases (Dnmts), including Dnmt1, Dnmt2, and Dnmt3a (Peng et al., 2015, 2017; Wang et al., 2016; Lewinska et al., 2018). Here, we show MIAT binds to the miR-34a promotor, and recruits Dnmt3a to methylate the promotor, leading to silencing of miR-34a expression.

\section{CONCLUSION}

Our findings demonstrate that silencing of MIAT sensitizes lung cancer cells to gefitinib by epigenetically miR-34a, and MIAT may be a useful prognostic marker and therapeutic target for lung cancer patients.

\section{AUTHOR CONTRIBUTIONS}

The study and experiments were conceived and designed by JL and RG. Patients were selected by: YF and CL. The experiments 
were performed by YL, LL, and CL. Analyzed and discussed the data and discussed the written manuscript: all authors. The manuscript was written by YF, CL, and RG. The figures and tables were constructed by YF, YL, and CL.

\section{REFERENCES}

Adams, B. D., Parsons, C., and Slack, F. J. (2016). The tumor-suppressive and potential therapeutic functions of miR-34a in epithelial carcinomas. Expert Opin. Ther. Targets 20, 737-753. doi: 10.1517/14728222.2016.1114102

Chen, W., Zheng, R., Baade, P. D., Zhang, S., Zeng, H., Bray, F., et al. (2016). Cancer statistics in China, 2015. CA Cancer J. Clin. 66, 115-132. doi: 10.3322/ caac. 21338

Chen, Y., Li, C., Pan, Y., Han, S., Feng, B., Gao, Y., et al. (2016). The emerging role and promise of long noncoding RNAs in lung cancer treatment. Cell. Physiol. Biochem. 38, 2194-2206. doi: 10.1159/000445575

Crea, F., Venalainen, E., Ci, X., Cheng, H., Pikor, L., Parolia, A., et al. (2016). The role of epigenetics and long noncoding RNA MIAT in neuroendocrine prostate cancer. Epigenomics 8, 721-731. doi: 10.2217/epi.16.6

De Marco, C., Laudanna, C., Rinaldo, N., Oliveira, D. M., Ravo, M., Weisz, A., et al. (2017). Specific gene expression signatures induced by the multiple oncogenic alterations that occur within the PTEN/PI3K/AKT pathway in lung cancer. PLOS ONE 12:e0178865. doi: 10.1371/journal.pone.0178865

Gong, J., Zhang, H., He, L., Wang, L., and Wang, J. (2017). Increased expression of long non-coding RNA BCAR4 is predictive of poor prognosis in patients with non-small cell lung cancer. Tohoku J. Exp. Med. 241, 29-34. doi: 10.1620/tjem. 241.29

Huang, X., Gao, Y., Qin, J., and Lu, S. (2017). LncRNA-MIAT promoted proliferation and invasion of HCC cells via sponging miR-214. Am. J. Physiol. Gastrointest. Liver Physiol. doi: 10.1152/ajpgi.00242.2017 [Epub ahead of print].

Ishii, N., Ozaki, K., Sato, H., Mizuno, H., Saito, S., Takahashi, A., et al. (2006). Identification of a novel non-coding RNA, MIAT, that confers risk of myocardial infarction. J. Hum. Genet. 51, 1087-1099. doi: 10.1007/s10038-0060070-9

Jiang, Q., Shan, K., Qun-Wang, X., Zhou, R. M., Yang, H., Liu, C., et al. (2016). Long non-coding RNA-MIAT promotes neurovascular remodeling in the eye and brain. Oncotarget 7, 49688-49698. doi: 10.18632/oncotarget.10434

Kim, Y. H., Lee, W. K., Lee, E. B., Son, J. W., Kim, D. S., and Park, J. Y. (2017). Combined Effect of metastasis-related MicroRNA, miR-34 and miR-124 family, methylation on prognosis of non-small-cell lung cancer. Clin. Lung Cancer 18, e13-e20. doi: 10.1016/j.cllc.2016.06.005

Kwon, H., Song, K., Han, C., Zhang, J., Lu, L., Chen, W., et al. (2017). Epigenetic silencing of miRNA-34a in human cholangiocarcinoma via EZH2 and DNA methylation: impact on regulation of notch pathway. Am. J. Pathol. 187, 2288-2299. doi: 10.1016/j.ajpath.2017.06.014

Lewinska, A., Adamczyk-Grochala, J., Kwasniewicz, E., Deregowska, A., Semik, E., Zabek, T., et al. (2018). Reduced levels of methyltransferase DNMT2 sensitize human fibroblasts to oxidative stress and DNA damage that is accompanied by changes in proliferation-related miRNA expression. Redox Biol. 14, 20-34. doi: 10.1016/j.redox.2017.08.012

Li, D. S., Ainiwaer, J. L., Sheyhiding, I., Zhang, Z., and Zhang, L. W. (2016). Identification of key long non-coding RNAs as competing endogenous RNAs for miRNA-mRNA in lung adenocarcinoma. Eur. Rev. Med. Pharmacol. Sci. 20, 2285-2295.

Li, H., Yuan, X., Yan, D., Li, D., Guan, F., Dong, Y., et al. (2017). Long non-coding RNA MALAT1 decreases the sensitivity of resistant glioblastoma cell lines to temozolomide. Cell. Physiol. Biochem. 42, 1192-1201. doi: 10.1159/000478917

Li, W., Li, N., Kang, X., and Shi, K. (2017). Circulating long non-coding RNA AFAP1-AS1 is a potential diagnostic biomarker for non-small cell lung cancer. Clin. Chim. Acta 475, 152-156. doi: 10.1016/j.cca.2017.10.027

Li, Y., Wang, K., Wei, Y., Yao, Q., Zhang, Q., Qu, H., et al. (2017). lncRNA-MIAT regulates cell biological behaviors in gastric cancer through a mechanism involving the miR-29a-3p/HDAC4 axis. Oncol. Rep. 38, 3465-3472. doi: 10.3892/or.2017.6020

Liao, H., Xiao, Y., Hu, Y., Xiao, Y., Yin, Z., Liu, L., et al. (2016). Methylation-induced silencing of miR-34a enhances chemoresistance by

\section{FUNDING}

This study was supported by Hunan Provincial Natural Science Foundation of China (Grant Nos. 2017JJ3463 and 2017JJ3467).

directly upregulating ATG4B-induced autophagy through AMPK/mTOR pathway in prostate cancer. Oncol. Rep. 35, 64-72. doi: 10.3892/or.2015.4331

Liao, J., He, Q., Li, M., Chen, Y., Liu, Y., and Wang, J. (2016). LncRNA MIAT: Myocardial infarction associated and more. Gene 578, 158-161. doi: 10.1016/j. gene.2015.12.032

Liu, B., Pan, C. F., Ma, T., Wang, J., Yao, G. L., Wei, K., et al. (2017). Long noncoding RNA AK001796 contributes to cisplatin resistance of nonsmall cell lung cancer. Mol. Med. Rep. 16, 4107-4112. doi: 10.3892/mmr.2017.7081

Luan, T., Zhang, X., Wang, S., Song, Y., Zhou, S., Lin, J., et al. (2017). Long non-coding RNA MIAT promotes breast cancer progression and functions as ceRNA to regulate DUSP7 expression by sponging miR-155-5p. Oncotarget 8, 76153-76164. doi: 10.18632/oncotarget.19190

Ma, P., Zhang, M., Nie, F., Huang, Z., He, J., Li, W., et al. (2017). Transcriptome analysis of EGFR tyrosine kinase inhibitors resistance associated long noncoding RNA in non-small cell lung cancer. Biomed. Pharmacother. 87, 20-26. doi: 10.1016/j.biopha.2016.12.079

Niu, Y., Ma, F., Huang, W., Fang, S., Li, M., Wei, T., et al. (2017). Long non-coding RNA TUG1 is involved in cell growth and chemoresistance of small cell lung cancer by regulating LIMK2b via EZH2. Mol. Cancer 16:5. doi: 10.1186/s12943016-0575-6

Peng, X., Chang, H., Chen, J., Zhang, Q., Yu, X., and Mi, M. (2017). 3,6Dihydroxyflavone regulates microRNA-34a through DNA methylation. BMC Cancer 17:619. doi: 10.1186/s12885-017-3638-1

Peng, X., Chang, H., Gu, Y., Chen, J., Yi, L., Xie, Q., et al. (2015). 3,6Dihydroxyflavone suppresses breast carcinogenesis by epigenetically regulating miR-34a and miR-21. Cancer Prev. Res. 8, 509-517. doi: 10.1158/1940-6207. CAPR-14-0357

Qu, C. H., Sun, Q. Y., Zhang, F. M., and Jia, Y. M. (2017). Long non-coding RNA ROR is a novel prognosis factor associated with non-small-cell lung cancer progression. Eur. Rev. Med. Pharmacol. Sci. 21, 4087-4091.

Qu, X., Du, Y., Shu, Y., Gao, M., Sun, F., Luo, S., et al. (2017). MIAT Is a Pro-fibrotic long non-coding RNA governing cardiac fibrosis in post-infarct myocardium. Sci. Rep. 7:42657. doi: 10.1038/srep42657

Rotow, J., and Bivona, T. G. (2017). Understanding and targeting resistance mechanisms in NSCLC. Nat. Rev. Cancer 17, 637-658. doi: 10.1038/nrc.2017.84

Saito, Y., Nakaoka, T., and Saito, H. (2015). microRNA-34a as a therapeutic agent against human cancer. J. Clin. Med. 4, 1951-1959. doi: 10.3390/jcm4111951

Schmid, G., Notaro, S., Reimer, D., Abdel-Azim, S., Duggan-Peer, M., Holly, J., et al. (2016). Expression and promotor hypermethylation of miR-34a in the various histological subtypes of ovarian cancer. BMC Cancer 16:102. doi: 10.1186/s12885-016-2135-2

Shen, Z., Zhou, C., Li, J., Ye, D., Li, Q., Wang, J., et al. (2016). Promoter hypermethylation of miR-34a contributes to the risk, progression, metastasis and poor survival of laryngeal squamous cell carcinoma. Gene 593, 272-276. doi: 10.1016/j.gene.2016.07.047

Siegel, R., Naishadham, D., and Jemal, A. (2013). Cancer statistics, 2013. CA Cancer J. Clin. 63, 11-30. doi: 10.3322/caac.21166

Stewart, E. L., Tan, S. Z., Liu, G., and Tsao, M. S. (2015). Known and putative mechanisms of resistance to EGFR targeted therapies in NSCLC patients with EGFR mutations-a review. Transl. Lung Cancer Res. 4, 67-81. doi: 10.3978/j. issn.2218-6751.2014.11.06

Sun, Y., Zhou, Y., Bai, Y., Wang, Q., Bao, J., Luo, Y., et al. (2017). A long noncoding RNA HOTTIP expression is associated with disease progression and predicts outcome in small cell lung cancer patients. Mol. Cancer 16:162. doi: 10.1186/s12943-017-0729-1

Tanaka, N., Toyooka, S., Soh, J., Kubo, T., Yamamoto, H., Maki, Y., et al. (2012). Frequent methylation and oncogenic role of microRNA-34b/c in small-cell lung cancer. Lung Cancer 76, 32-38. doi: 10.1016/j.lungcan.2011.10.002

Tian, H., Zhou, C., Yang, J., Li, J., and Gong, Z. (2017). Long and short noncoding RNAs in lung cancer precision medicine: opportunities and challenges. Tumour Biol. 39:1010428317697578. doi: 10.1177/1010428317697578 
Torre, L. A., Bray, F., Siegel, R. L., Ferlay, J., Lortet-Tieulent, J., and Jemal, A. (2015). Global cancer statistics, 2012. CA Cancer J. Clin. 65, 87-108. doi: 10.3322/caac. 21262

Wang, L., Bu, P., Ai, Y., Srinivasan, T., Chen, H. J., Xiang, K., et al. (2016). A long non-coding RNA targets microRNA miR-34a to regulate colon cancer stem cell asymmetric division. eLife 5:e14620. doi: 10.7554/eLife.14620

Wang, P., Chen, D., Ma, H., and Li, Y. (2017). LncRNA MEG3 enhances cisplatin sensitivity in non-small cell lung cancer by regulating miR-21-5p/SOX7 axis. Onco Targets Ther. 10, 5137-5149. doi: 10.2147/OTT.S146423

Xue, W., Li, L., Tian, X., Fan, Z., Yue, Y., Zhang, C., et al. (2017). Integrated analysis profiles of long non-coding RNAs reveal potential biomarkers of drug resistance in lung cancer. Oncotarget 8, 62868-62879. doi: 10.18632/oncotarget.16444

Yan, B., Yao, J., Liu, J. Y., Li, X. M., Wang, X. Q., Li, Y. J., et al. (2015). IncRNAMIAT regulates microvascular dysfunction by functioning as a competing endogenous RNA. Circ. Res. 116, 1143-1156. doi: 10.1161/CIRCRESAHA.116. 305510

Zhang, H. Y., Zheng, F. S., Yang, W., and Lu, J. B. (2017). The long non-coding RNA MIAT regulates zinc finger E-box binding homeobox 1 expression by sponging miR-150 and promoting cell invasion in non-small-cell lung cancer. Gene 633, 61-65. doi: 10.1016/j.gene.2017.08.009

Zhang, K., and Yuan, Q. (2016). Current mechanism of acquired resistance to epidermal growth factor receptor-tyrosine kinase inhibitors and updated therapy strategies in human nonsmall cell lung cancer. J. Cancer Res. Ther. 12, C131-C137. doi: 10.4103/0973-1482.200613

Zhao, J., Guerrero, A., Kelnar, K., Peltier, H. J., and Bader, A. G. (2017). Synergy between next generation EGFR tyrosine kinase inhibitors and miR-34a in the inhibition of non-small cell lung cancer. Lung Cancer 108, 96-102. doi: 10.1016/ j.lungcan.2017.02.020

Zhou, J. Y., Chen, X., Zhao, J., Bao, Z., Chen, X., Zhang, P., et al. (2014). MicroRNA34a overcomes HGF-mediated gefitinib resistance in EGFR mutant lung cancer cells partly by targeting MET. Cancer Lett. 351, 265-271. doi: 10.1016/j.canlet. 2014.06.010

Zhou, X., Zhang, W., Jin, M., Chen, J., Xu, W., and Kong, X. (2017). IncRNA MIAT functions as a competing endogenous RNA to upregulate DAPK2 by sponging miR-22-3p in diabetic cardiomyopathy. Cell Death Dis. 8:e2929. doi: $10.1038 /$ cddis.2017.321

Zhu, M., Li, N., Luo, P., Jing, W., Wen, X., Liang, C., et al. (2017). Peripheral blood leukocyte expression of lncRNA MIAT and its diagnostic and prognostic value in ischemic stroke. J. Stroke Cerebrovasc. Dis. 27, 326-337. doi: 10.1016/j. jstrokecerebrovasdis.2017.09.009

Conflict of Interest Statement: The authors declare that the research was conducted in the absence of any commercial or financial relationships that could be construed as a potential conflict of interest.

Copyright (C) $2018 \mathrm{Fu}, \mathrm{Li}, \mathrm{Luo}, \mathrm{Li}$, Liu and Gui. This is an open-access article distributed under the terms of the Creative Commons Attribution License (CC BY). The use, distribution or reproduction in other forums is permitted, provided the original author(s) and the copyright owner are credited and that the original publication in this journal is cited, in accordance with accepted academic practice. No use, distribution or reproduction is permitted which does not comply with these terms. 